\title{
Magmatismo nas bacias sedimentares brasileiras e sua influência na geologia do petróleo
}

\author{
Antonio Thomaz Filho ${ }^{1}$, Ana Maria Pimentel Mizusaki ${ }^{2}$ \& Luzia Antonioli $^{1}$
}

\begin{abstract}
Resumo As pesquisas realizadas nos últimos anos sobre os eventos magmáticos presentes nas bacias sedimentares brasileiras têm mostrado a importância desses episódios para a exploração de hidrocarbonetos. Citam-se os casos da geração (aquecimento), migração (alterações estruturais e petrográficas), acumulação (basaltos fraturados) e barreira (diques e soleiras) dos hidrocarbonetos, produzidos por essas rochas, tanto nas bacias sedimentares marginais como nas intracontinentais. O magmatismo é acompanhado pelo aumento da temperatura da bacia nos arredores de sua intrusão o que produz o aquecimento das rochas geradoras de hidrocarbonetos e, assim, possibilita a maturação da matéria orgânica nela contida. Ao mesmo tempo, tem sido verificado que os contatos diques / rochas sedimentares podem ter propiciado importantes caminhos para a migração dos hidrocarbonetos. Estudos recentes têm mostrado que o magmatismo deve merecer análises mais pormenorizadas até mesmo em suas manifestações extrusivas, tendo em vista as perspectivas de terem atuado como efetivos selantes e, em conseqüência, possibilitando a acumulação de hidrocarbonetos gerados nos sedimentos subjacentes. O magmatismo de caráter predominantemente básico a intermediário tem sua gênese na astenosfera, ou seja, abaixo da litosfera. Assim sendo, mesmo os diques que se introduziram no embasamento das nossas bacias sedimentares merecem cuidadosa atenção, posto que rochas são boas condutoras de calor e, sobre esses diques, podem ser prognosticados maiores gradientes geotérmicos presentes nos depósitos sedimentares sobrepostos. O melhor entendimento dos processos magmáticos presentes nas bacias sedimentares brasileiras deve conduzir a estudos sobre novas formas de exploração de hidrocarbonetos em nossas bacias sedimentares, inclusive naquelas em que as atividades de exploração tradicional não têm surtido os sucessos esperados.
\end{abstract}

Palavras-chave: Bacias sedimentares brasileiras, magmatismo, exploração de petróleo.

\begin{abstract}
Magmatism in the brazilian sedimentary basins and the petroleum geology. In the recent years, the researches on the magmatic events that occurred in the Brazilian sedimentary basins had shown the importance of these episodes for the hydrocarbons exploration. The generation (heating), migration (structural and petrografic alterations), accumulation (basalt fractures) and migrations barriers (sills and dykes) of the hydrocarbons, produced for these rocks, are cited in the marginal and intracontinental Brazilian basins. The magmatism produce the temperature increase in the sedimentary basin, around its intrusion, and this propitiate the maturation of the organic matter contained in the hydrocarbons generating rocks of the basin. At the same time, has been verified that the contacts dykes/sedimentary rocks can represent important ways for the hydrocarbons migrations. Recent studies have shown that the magmatism, in its extrusive manifestations, can be analyzed in view of the possibility of having acted as effective hydrocarbon seals and, in consequence, making possible the accumulation of hydrocarbons generated in the underlying sediments. The magmatism of predominantly basic to intermediary character is generated in the asthenosphere, that is, below the lithospere. The dykes that had introduced in the basement of our sedimentary basins are good heat conductors and we can expect the geothermal gradients increase in the overlapped sedimentary deposits. The more detailed study of the magmatic processes in the Brazilian sedimentary basins must lead to new forms of hydrocarbons exploration in our sedimentary basins, also in those basins where the traditional exploration activities have not occasioned the waited expected successes.
\end{abstract}

Keywords: Brazilian sedimentary basins, magmatism, petroleum exploration.

INTRODUÇÃo Este trabalho sintetiza inúmeras pesquisas que têm sido realizadas no sentido de analisar as intrusões e extrusões de rochas magmáticas predominantemente básicas a intermediárias como possíveis fatores favoráveis à geração, migração e acumulação de hidrocarbonetos. A ação do calor dessas rochas propicia a maturação da matéria orgânica contida nas rochas geradoras de hidrocarbonetos. Além disso, pode originar eventos favoráveis aos processos de migração (devido às significativas variações petrofísicas que produzem nas pressões hidrostáticas dos poros das rochas) e de acumulação de petróleo (diques e soleiras de diabásio). 
Mizusaki et al. (1998) e Thomaz-Filho et al. (2000), ao analisarem o rifteamento que causou a separação entre os continentes Sul-Americano e Africano, utilizaram-se dos resultados de 377 datações radiométricas Potássio/ Argônio de amostras de rochas magmáticas básicas e alcalinas que ocorrem nas bacias sedimentares brasileiras para elaborar o histograma mostrado na figura 1. A relação dessas rochas, nos seus aspectos de localização, tipo, material analisado e idades obtidas, está disponível no trabalho de Mizusaki et al. (2002).

Na figura 1, pode-se observar o ápice dos principais eventos magmáticos que atingiram as bacias sedimentares brasileiras:

(1) ao redor de $215 \mathrm{Ma}$ (Triássico) e (2) ao redor de $180 \mathrm{Ma}$ (Jurássico): diques e derrames de composição toleítica;

(3) ao redor $130 \mathrm{Ma}$ (Neocomiano): derrames e diques de composição toleítica e intermediária; ( 4 ) maior incidência entre 80 a $90 \mathrm{Ma}$ (Santoniano/Turoniano) - predominam intrusões de composição básica a intermediária;

(5) maior incidência entre 40 a $60 \mathrm{Ma}$ (Eoceno) e (6) idades inferiores a $50 \mathrm{Ma}$ (Eoceno ao Recente): normalmente sob a forma de cones vulcânicos de composição intermediária a alcalina.

Os dois grandes episódios magmáticos do Triássico e do Jurássico estão muito bem representados nas bacias paleozóicas do Solimões e do Amazonas. Os eventos do Triássico, do Jurássico e do Neocomiano estão presentes na Bacia do Parnaíba. Este último evento, do Neocomiano, ocorreu de forma muito intensa na Bacia do Paraná, vindo a constituir os imensos derrames de basalto da Formação Serra Geral. Três outros picos destacam-se no histograma da figura 1. Um deles é do Santoniano/Turoniano (há cerca de $90 \mathrm{Ma}$ ) a que Thomaz-Filho et al. (2000) associaram à separação definitiva entre os continentes Sul-Americano e Africano, até então ligados apenas na margem leste brasileira.

Os dois últimos eventos resultam de magmatismos pontuais resultantes da ação de "hot spots", quando o continente Sul-Americano passou a derivar-se para oeste e afastar-se do continente Africano. O pico mostrado no Eoceno (há cerca de $50 \mathrm{Ma}$ ) resultou do grande magmatismo que ocorreu, naquela época, na margem sudeste brasileira, nas regiões de Cabo Frio (RJ), Bacia de Campos e Arquipélago de Abrolhos (ES). O magmatismo salientado no Oligoceno (há cerca de $10 \mathrm{Ma}$ ) mostra que a ação de "hot spots" tem sido contínua durante a deriva continental e provavelmente continua até os dias atuais.

É objetivo do presente estudo analisar esses eventos magmáticos de caráter básico a intermediárioalcalino que ocorreram nas bacias sedimentares brasileiras em diferentes períodos geológicos e buscar suas associações com as ocorrências de hidrocarbonetos nessas bacias.

MAGMATISMO NAS BACIAS PALEOZÓICAS BRASILEIRAS As bacias sedimentares paleozóicas brasileiras do Paraná, Parnaíba e Amazonas caracteri-

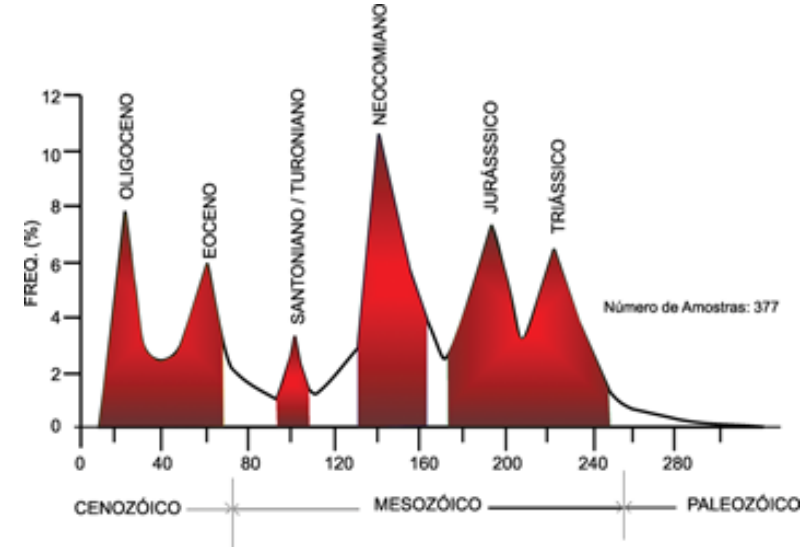

Figura 1 - Datações radiométricas $K / A r$ de rochas magmáticas básicas e alcalinas e suas relações com o tempo geológico (modificado de ThomazFilho et al. 2000).

zam-se pela carência de deformações estruturais intensas, normalmente associadas a faixas de dobramentos desenvolvidas pelos encontros de placas tectônicas. Essas características as diferenciam das grandes bacias paleozóicas da Plataforma do Leste Europeu altamente produtoras de hidrocarbonetos, estas últimas sim com deformações estruturais bem desenvolvidas devido às faixas móveis tectônicas que de alguma forma as contornaram em diferentes períodos de sua evolução. No Brasil, a exceção é a bacia paleozóica do Solimões que, pela ação do tectonismo andino, desenvolveu altos estruturais derivados de eventos transcorrentes (Caputo \& Silva 1990).

Thomaz-Filho (1982), Araújo et al. (2005, 2006) e Thomaz-Filho et al. (2008) realizaram pesquisas que enfocaram a influência dos eventos magmáticos que afetaram as bacias paleozóicas brasileiras e que, de alguma forma, poderiam estar relacionados com a ocorrência de petróleo. A Bacia do Paraná foi melhor estudada pelos autores, tendo em vista as ocorrências dos arenitos asfálticos da Formação Pirambóia que afloram no leste do Estado de São Paulo. Os estudos detalhados dessas ocorrências permitiram elaborar um modelo de geração, migração e acumulação de petróleo que, por analogia, pode ser aplicado em outras partes da Bacia do Paraná e, mesmo, nas outras bacias paleozóicas brasileiras, com o objetivo de buscar novas oportunidades de exploração de hidrocarbonetos.

O magmatismo, preferencialmente básico, que afetou as bacias do Paraná, Parnaíba, Amazonas e Solimões teve início no Triássico (há cerca de $215 \mathrm{Ma}$ ), quando ocorreu o início da quebra continental entre os continentes Sul-Americano e Africano (Almeida 1986, Thomaz-Filho et al. 2000). Esse magmatismo teve caráter intrusivo (diques e soleiras de diabásio) e extrusivo (derrames de basalto) e encontra-se presente no sul da América do Sul (dando início à abertura do Oceano Atlântico Sul) e na Bacia da Foz do Amazonas (dando início à abertura do Oceano Atlântico Norte). Magmatismo com as mesmas características ocorreu 
até o Neocomiano (há cerca de $130 \mathrm{Ma}$ ), marcando o processo de rifteamento que deu origem às bacias marginais brasileiras e africanas e que se extravasou para as bacias paleozóicas do Paraná e do Parnaíba e no continente Africano (Província Ígnea de Etendeka, na Namíbia, Siedner \& Mitchell 1976). Nas bacias marginais ocorreram diques e derrames de rochas ígneas básicas de idades semelhantes intercaladas nos sedimentos depositados em ambientes continentais durante o estágio rifte dessas bacias.

$\mathrm{O}$ efeito termal que as intrusões ígneas básicas produzem nas rochas sedimentares foi analisado por Rodrigues (1995), na Bacia do Parnaíba, e Alves e Rodrigues (1985), na Bacia do Amazonas. Estes últimos autores chegaram à conclusão que o efeito da intrusão na encaixante é equivalente à espessura do corpo intrusivo. No caso de intrusões múltiplas, supõem que o efeito poderia ser potencializado. Esse processo pode variar em suas dimensões em função da profundidade em que se implantou a intrusão, sendo maior o calor transmitido quanto maior for a profundidade.

Considerando que nas bacias paleozóicas brasileiras ocorrem boas rochas geradoras de hidrocarbonetos no Devoniano e no Permiano, é lícito prognosticar que grandes quantidades de petróleo podem ter sido geradas pela ação dos corpos ígneos intrusivos nessas bacias. Se, concomitante com essa geração, ocorreram eventos de migração e acumulação do petróleo, é de se esperar que acumulações de hidrocarbonetos possam ser encontradas nessas bacias (Figueiredo \& Milani 2002).

Com base nessas perspectivas, Thomaz-Filho et al. (2008) retornaram às pesquisas desenvolvidas por Thomaz-Filho (1982) sobre as ocorrências de arenitos asfálticos na Formação Pirambóia da Bacia do Paraná, aflorantes na região leste do Estado de São Paulo (Fig. 2). Neste último trabalho, foi analisada a exsudação de óleo de Anhembi, uma das maiores daquela região. Foram realizados 26 furos de sondagem com testemunhagem e perfilagem (raios gama, potencial espontâneo e resistividade) contínuas até a base da Formação Pirambóia, no seu contato com a Formação Teresina. Com as informações obtidas nessas perfurações foram elaborados dois mapas: a) contorno estrutural da base da Formação Pirambóia; e b) variações da espessura do arenito impregnado de óleo (Fig. 3).

O petróleo ocorre nas fácies fluviais e eólicas da seção inferior da Formação Pirambóia e, pelas análises geoquímicas já realizadas, teve a Formação Irati como seu gerador, mais especificamente o Membro Assistência (Araújo et al. 2000). Trata-se de óleo imaturo e pesado (cerca de $5^{\circ} \mathrm{API}$ ), onde a maturação da matéria orgânica deveu-se à ação térmica das intrusões ígneas básicas do Cretáceo Inferior na Bacia do Paraná. Araújo et al. (2000) concluíram tratar-se de um sistema petrolífero atípico, onde o magmatismo produziu um sincronismo de eventos de maturação, migração e acumulação de petróleo, como já havia sido proposto por Thomaz-Filho (1982). Conforme pode ser observado na figura 3 , tanto a distribuição da espessura do arenito

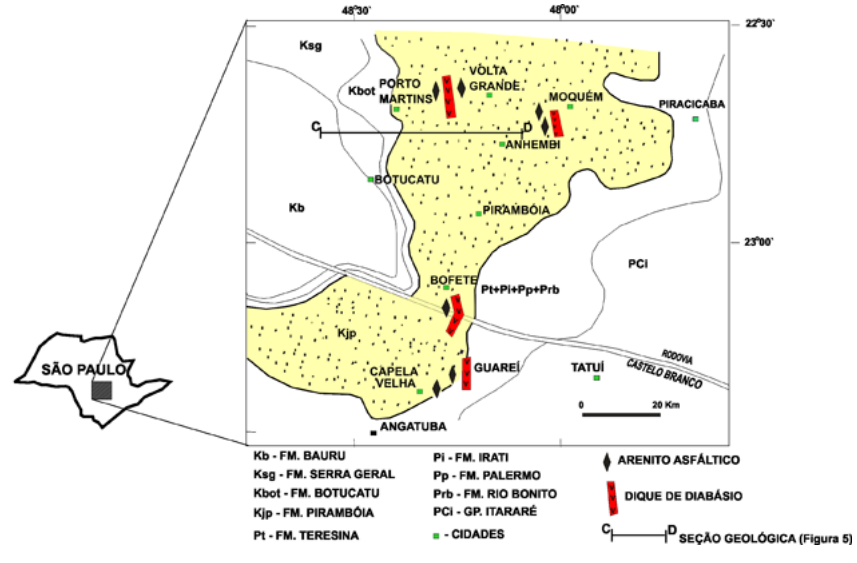

Figura 2 - Exsudações de óleo na Formação Pirambóia da Bacia do Paraná, no leste do Estado de São Paulo (modificado de Thomaz-Filho 1982).

impregnado pelo óleo, quanto as informações do mapa de contorno estrutural da base da Formação Pirambóia, mostram que a acumulação foi controlada por um alto estrutural e o dique de diabásio atuou como uma barreira para a migração horizontal do petróleo.

Observa-se na figura 4, que o óleo migrou a partir da Formação Irati para os arenitos Pirambóia ao longo do contato dique de diabásio / rochas sedimentares. Essa hipótese pode ser aceita pelo fato de, ao longo do mesmo nível estratigráfico da seção impregnada, ser evidente que o conteúdo de óleo no arenito cresce progressivamente na medida em que se distancia do dique. O maior teor de óleo nos intervalos estratigráficos mais rasos é indicativo de que a distribuição do óleo obedeceu à melhor permo-porosidade do arenito nas regiões com menor pressão hidrostática.

Nas exsudações melhor conhecidas do leste do Estado de São Paulo, observa-se que as acumulações de óleo ocorrem restritas do lado interno dos diques com direções preferenciais N-S, ou seja, lado oeste dos diques ou do lado bacia adentro (Fig. 2). Essa direção preferencial dos diques é necessária tendo em vista ser aproximadamente perpendicular ao sentido do mergulho das camadas sedimentares da Bacia do Paraná, naquela região. Assim sendo, ocorreu o fluxo hidrodinâmico do interior para os afloramentos das rochas sedimentares da bacia, com os diques atuando como barreiras no sentido horizontal de migração do óleo. No lado bacia afora do dique, ou seja, lado leste, ainda não foram observadas acumulações de óleo nos arenitos Pirambóia.

Do exposto, pode-se concordar com o proposto por Rodrigues (1995) que considerou, no caso da ação do magmatismo como agente do sistema petrolífero, que as condições de migração e acumulação de petróleo ocorram no momento em que a intrusão provocou a maturação da matéria orgânica nas rochas geradoras. Este é o caso da acumulação de hidrocarbonetos nos arenitos betuminosos da exsudação de Anhembi.

$\mathrm{O}$ alto estrutural da acumulação de Anhembi, 


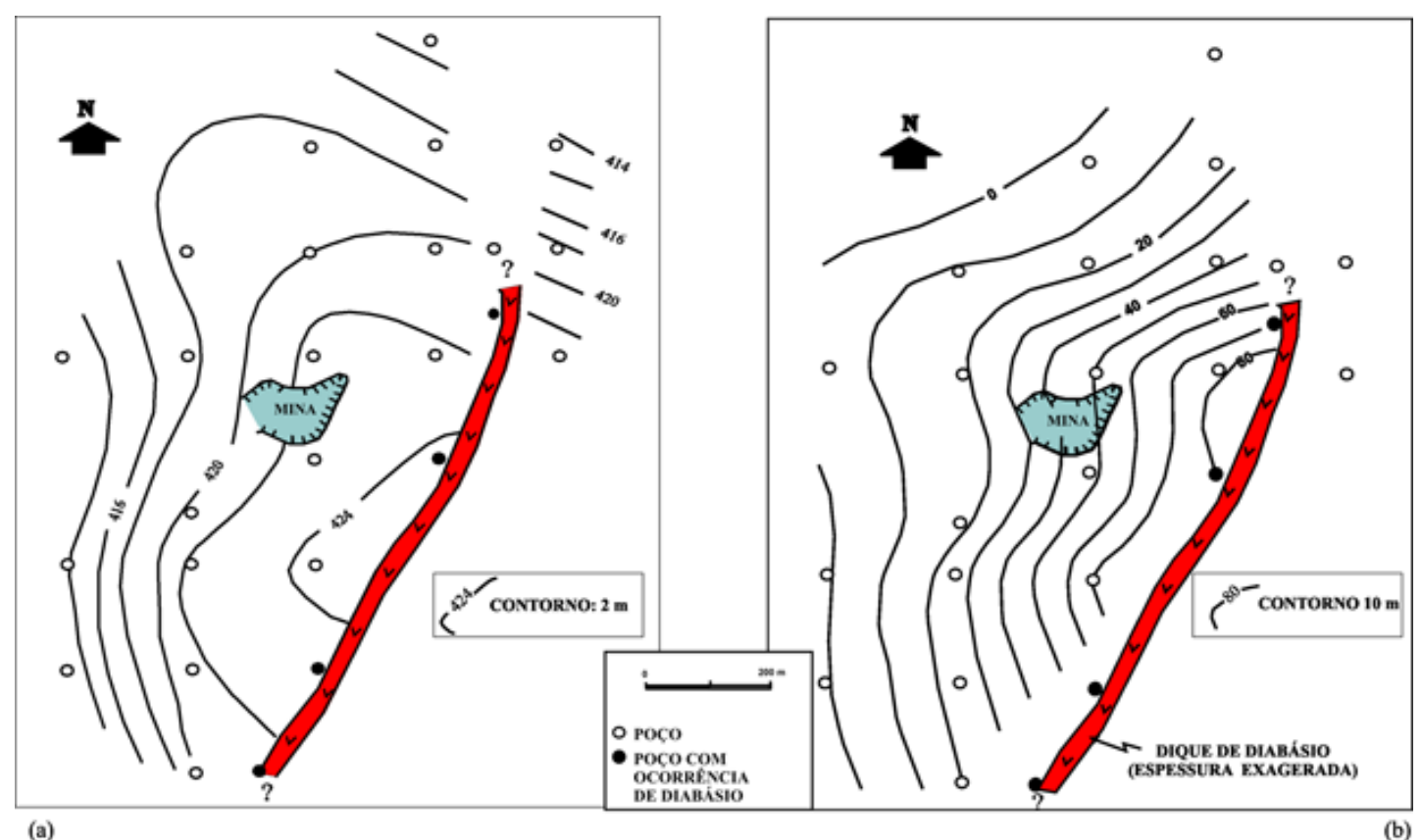

(a)

Figura 3 - (a) Mapa de contorno estrutural da base da Formação Pirambóia, na área da exsudação de óleo de Anhembi (Estado de São Paulo) e (b) mapa das variações de espessura do arenito Pirambóia impregnado de óleo (modificado de Thomaz-Filho 1982).

conforme mostrado na figura 3, pode ser explicado pelo que foi exposto por Conceição et al. (1993), quando se referiu aos anticlinais e sinclinais periféricos aos diques de diabásio que se introduziram nas bacias sedimentares. Devido às diferenças de espessuras do dique, podem ocorrer processos diferenciados de arraste dos sedimentos, com maior intensidade onde o dique apresenta espessuras maiores e, assim, tende a formar os anticlinais periféricos. Os aspectos estruturais da região leste do Estado de São Paulo, onde afloram os arenitos asfálticos da Formação Pirambóia, foram estudados por Araújo et al. (2005 e 2006). Estes autores definiram o Complexo Estrutural de Jacu e a Área Alta de Anhembi e verificaram que os diques de diabásio estão associados a altos estruturais.

A partir do modelo de acumulação de óleo na exsudação de Anhembi, pode-se prognosticar que um sistema petrolífero similar pode ter ocorrido em outras partes, não só na Bacia do Paraná, como nas demais bacias paleozóicas brasileiras. Assim sendo, é admissível a hipótese de que sob o magmatismo da Formação Serra Geral da Bacia do Paraná tenha ocorrido evento semelhante, conforme proposto na figura 5. Caso isso tenha ocorrido, e considerando que o basalto tenha atuado como selante e impedido a perda total dos hidrocarbonetos, como estariam hoje essas acumulações? Para tanto, fazem-se necessários estudos geofísicos que tenham resolução nas formações sedimentares sob a Formação Serra Geral para detectar os diques de diabásio, suas direções preferenciais em relação ao sentido de mergulho das camadas sedimentares e, ainda, que seja possível detectar os anticlinais periféricos situados no lado desses diques voltado para o interior da bacia sedimentar.

\section{MAGMATISMO NAS BACIAS SEDIMENTARES MARGINAIS}

Magmatismo do Neocomiano $\mathrm{O}$ intenso magmatismo do Neocomiano que veio a constituir a seqüência de derrames de basalto da Formação Serra Geral na Bacia do Paraná também manifestou-se de forma significativa nas bacias marginais, fruto do extravasamento do magma astenosférico que chegou próximo da superfície, quando do processo de rifteamento que separou os continentes Sul-Americano e Africano. Conforme analisado por Thomaz-Filho et al. (2006), baseado nas informações obtidas em diversos autores (Dias et al. 1994, Pereira \& Feijó 1994, Ragel et al. 1994, Santos et al. 1994, Vieira et al. 1994), o início do estágio rifte nas margens sudeste e leste brasileira teve início há cerca de $143 \mathrm{Ma}$ (definido pela discordância sin-rifte), desde a Bacia do Espírito Santo até as bacias de rifte abortado do Recôncaco, Tucano e Jatobá. No caso das bacias de Pelotas, Santos e Campos, o rifte teria se iniciado nessa mesma idade, ou até antes disso, o que implica na possibilidade real da existência de sedimentos sotopostos e ocultados pelos basaltos do Neocomiano, considerado o embasamento econômico dessas bacias. É lícito prognosticar que, no período entre 143 Ma e o ápice do magmatismo do Neocomiano, ocorrido há cerca de 132 Ma, teriam se depositado os sedimentos continentais do estágio rifte intercalados com eventos magmáticos, como observado na Bacia do Espírito Santo. É oportuno salientar que o período entre 143 e 132 Ma coincide com a sedimentação de rochas geradoras nas nossas bacias marginais, caso das formações Cricaré, na Bacia 


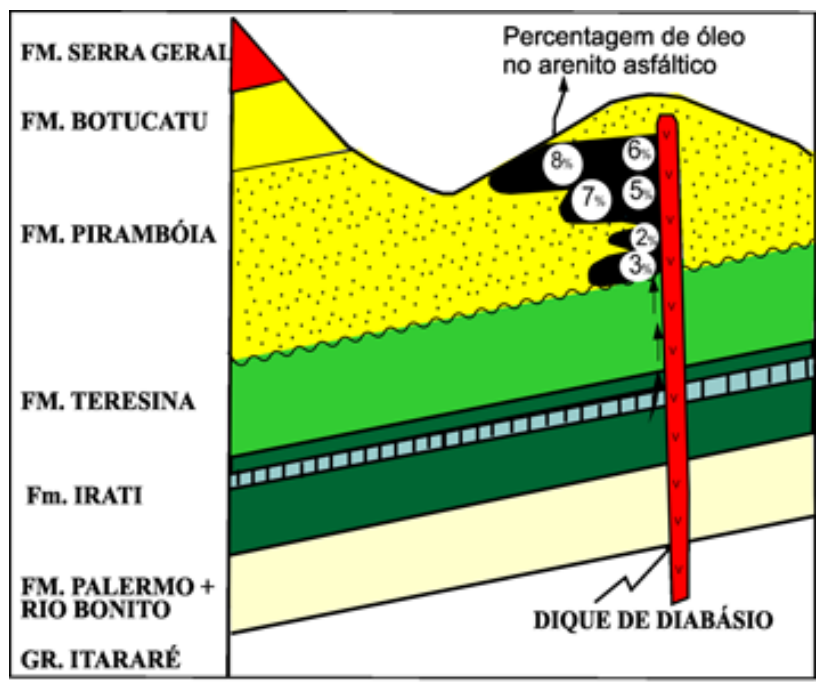

SEM ESCALA

Figura 4 - A migração do óleo da Formação Irati para o arenito reservatório da Formação Pirambóia na exsudação de Anhembi, Estado de São Paulo (modificado de Thomaz-Filho 1982).

do Espírito Santo, e Candeias, na Bacia do Recôncavo. $\mathrm{O}$ mesmo pode ter acontecido por sob os basaltos considerados o embasamento econômico das bacias de Campos, Santos e Pelotas. Em outras palavras, é possí- vel ocorrer sedimentos da fase rifte sob esses basaltos. Se tal efetivamente ocorreu, qual teria sido a influência do magmatismo do Neocomiano nessas bacias, tanto sob o aspecto do efeito térmico que provocou, quanto das suas propriedades como selante dos hidrocarbonetos gerados? Essa é uma perspectiva altamente atraente para as pesquisas futuras de hidrocarbonetos nessas bacias sedimentares.

Na Bacia de Campos, o magmatismo do Neocomiano é um exemplo de reservatório em rochas magmáticas com produção de hidrocarbonetos nos campos de Badejo e Linguado. O reservatório constitui-se de derrames onde a porosidade por fraturamento é a dominante. O preenchimento deste reservatório ocorreu a partir de intenso falhamento que colocou em contato lateral os geradores e os derrames básicos. Este tipo de reservatório foi um dos principais objetivos no início da exploração da bacia, mas depois ficou em segundo plano em virtude do sucesso obtido com outros prospectos (Eiras \& Wanderley Filho 2004).

Magmatismo do Cretáceo Superior O trabalho de Thomaz-Filho et al. (2006) apresentou as conclusões preliminares de uma revisão tectono/estratigráfica das bacias marginais brasileiras que se encontra em desenvolvimento na Faculdade de Geologia da UERJ. Nesse trabalho, constatou-se que o magmatismo básico a básico-alcalino do Cretáceo Superior (de idades próximas de $90 \mathrm{Ma})$, que ocorre nessas bacias, estaria associado

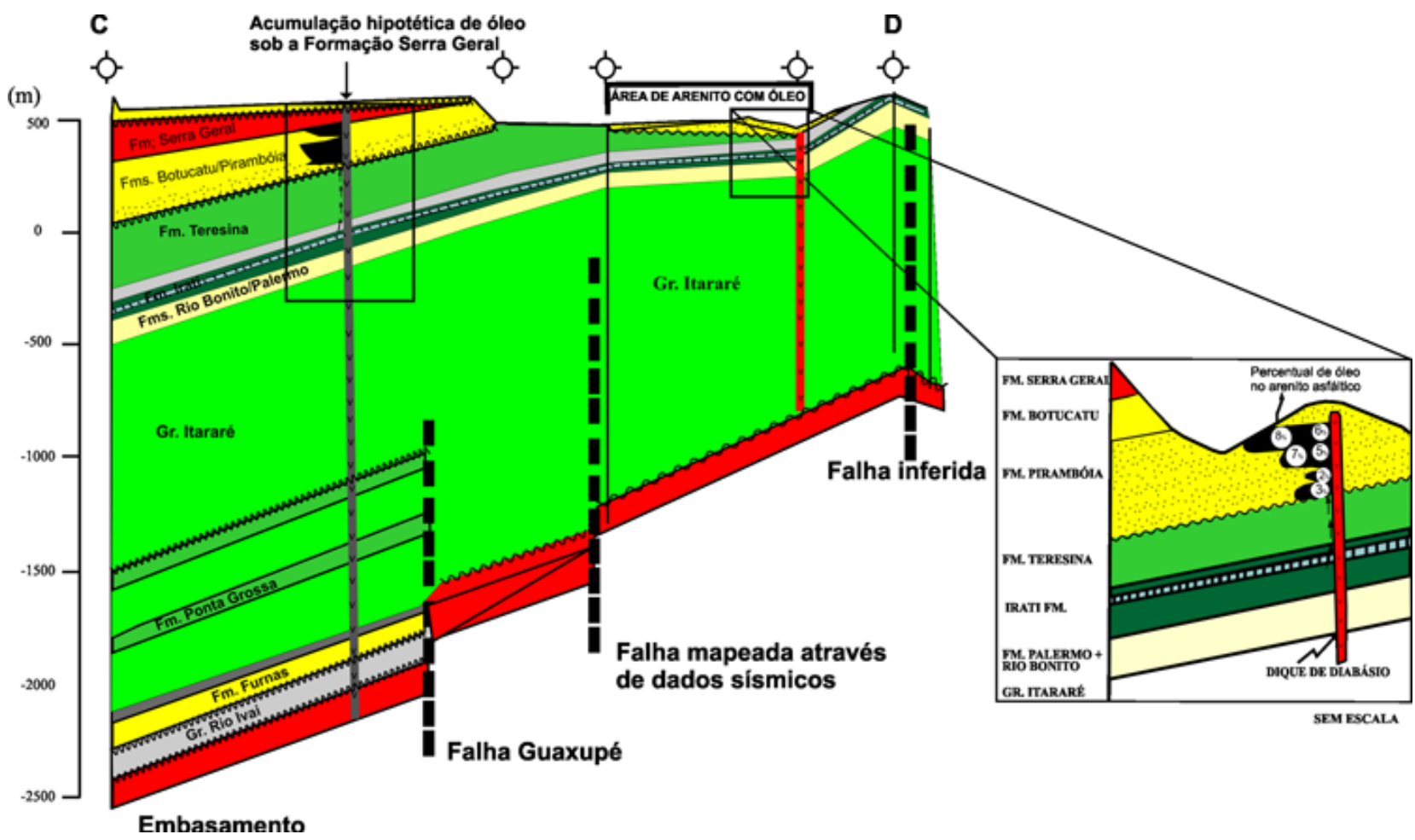

Figura 5 - Seção geológica da Bacia do Paraná, incluindo as exsudações de óleo do leste do Estado de São Paulo (modificado de Araújo et al. 2000), e mostrando uma hipotética acumulação de óleo abaixo da Formação Serra Geral, similar àquela da exsudação de Anhembi (modificado de Thomaz-Filho et al. 2008). 
à quebra definitiva entre os continentes Sul-Americano e Africano. Conforme o histograma da figura 1, o pico ali apresentado de $90 \mathrm{Ma}$ corresponderia efetivamente ao momento em que essa quebra ocorreu e o continente Sul-Americano passou a deslocar-se em sua deriva para oeste e, conseqüentemente, a separar-se em definitivo do continente Africano.

A separação final entre os continentes produziu, nas bacias marginais, uma marcante discordância sedimentar próxima, ou no topo, das plataformas carbonáticas presentes nessas bacias. Assim, a discordância teria sido o resultado da abrupta entrada do mar nas bacias marginais, o que ocasionou a passagem de um ambiente nerítico, relativamente raso, para ambiente de profundidades abissais. Isso provocou o afogamento das plataformas carbonáticas e a subseqüente sedimentação das seqüências marinhas profundas por sobre essas plataformas.

Pode-se considerar que o estágio de mar nerítico (normalmente associado à sedimentação carbonática) tem como comparação o Golfo do Aden e apresenta profundidades de lâmina d'água de até 200 metros, considerado como o limite da Plataforma Continental atual. Nas bacias da margem sudeste e leste do Brasil, da Bacia de Pelotas até a Bacia de Pernambuco/Paraíba, excetuando-se as bacias do Recôncavo, Tucano e Jatobá, o estágio de mar restrito iniciou-se há cerca de $112 \mathrm{Ma}$ e encerrou-se há cerca de $90 \mathrm{Ma}$. O estágio de mar abissal e batial iniciou-se há cerca de $90 \mathrm{Ma}$ em todas as bacias marginais brasileiras e persiste até o presente. Essas mesmas interpretações são propostas para as bacias situadas na margem equatorial brasileira, nesse caso com um pouco mais de complicação devido ao evento de transcorrência que afetou essas bacias. De qualquer forma, nelas foram identificados os três estágios rifte, mar restrito e mar nerítico, com a implantação do mar batial e abissal também ocorrendo há cerca de $90 \mathrm{Ma}$.

Que modificações estruturais teriam se desenvolvido nas bacias marginais nesse momento geológico, ou, mesmo, teriam ocorrido eventos que propiciassem a geração, migração e acumulação de petróleo nessas bacias? São propostas a serem consideradas pelos exploracionistas.

Magmatismo do Eoceno O magmatismo básico e básico-alcalino do Terciário, com intensa manifestação no Eoceno (há cerca de $50 \mathrm{Ma}$ ) e com idades mais jovens, desenvolveu-se durante o deslocamento para oeste da Placa Sul-Americana e é atribuído à presença de "hot spots" abaixo da litosfera (Thomaz-Filho \& Rodrigues 1999, Thomaz-Filho et al 2005). Sua composição química e mineralógica foi controlada, muito provavelmente, pela assimilação crustal das rochas litosféricas atravessadas pelo magma ascendente da astenosfera. Os citados autores propuseram que o continente SulAmericano se moveu sobre um "hot spot" que marcou sua passagem nas diferentes manifestações vulcânicas hoje conhecidas como Alinhamento de Rochas Alcalinas Poços de Caldas (MG) - Cabo Frio (RJ) (Herz
1977, Cordani \& Teixeira 1979, Sadowski \& Dias Netto 1981, Fletcher \& Litherland 1981, Fodor et al. 1983, Almeida 1983 e 1991). Quando o "hot spot" chegou à região de Cabo Frio, o continente Sul-Americano experimentou um movimento rotacional, no sentido dextral, que fez com que ele passasse a se manifestar a partir da extremidade oeste da Cadeia Vitória Trindade, provavelmente ainda há cerca de $50 \mathrm{Ma}$ e, hoje, encontra-se próximo da Ilha de Trindade (Thompson et al. 1998, Thomaz-Filho \& Rodrigues 1999, ThomazFilho et al. 2005). Essa rotação fez com que a Bacia de Campos viesse a mover-se por sobre esse "hot spot" e, coincidentemente, o traçado por onde ele teria passado justapõe-se ao notável alinhamento na direção NE dos campos de petróleo da Bacia de Campos (Fig. 6). Algumas evidências magmáticas, paleomagnéticas, gravimétricas e tectônicas de que isso teria ocorrido foram expostas por Thomaz-Filho et al. (2005).

A evidência magmática é representada pelo intenso vulcanismo de idade eocênica, tanto no Alto de Cabo Frio (RJ), quanto no Arquipélago de Abrolhos (ES) (Cordani 1970, Cordani \& Blazecovic 1970). Na região da Plataforma de Cabo Frio da Bacia de Campos, foram identificados, em seções sísmicas e poços perfurados na Bacia de Campos, cones vulcânicos, diques e soleiras introduzidos na seqüência sedimentar da bacia (Macedo et al. 1991, Mohriak et al. (inédito), 1992, Mizusaki \& Mohriak 1992, Mohriak 2004). Como mostrado na figura 7, as bacias marginais de Pelotas, Santos, Campos, Espírito Santo, Cumuruxatiba e Jequitinhonha registram pronunciada discordância no Eoceno, assim como a intrusão de rochas magmáticas de idade semelhante (Mizusaki et al. 1994).

Uma outra evidência relacionada ao magmatismo na Bacia de Campos pode ser observada no trabalho de Scarton (1993), quando traçou, a partir de dados de poço, a curva de subsidência (mecânica + termal) obtida pela retrodenudação (backstripping) do empilhamento sedimentar e comparou essa curva com a curva de subsidência teórica obtida pelo método desenvolvido por McKenzie (1978) (Fig. 8). Verifica-se que a curva obtida a partir dos dados de poços mostra um importante soerguimento termal do embasamento, chegando localmente até a $700 \mathrm{~m}$, coevo com os eventos vulcânicos de cerca de 50 Ma. Segundo Scarton (1993), esses eventos magmáticos estiveram associados a pulsos vulcânicos descontínuos.

A evidência paleomagnética foi identificada por Ernesto (1996) e Ernesto et al. (2002) quando sugeriram que o continente Sul-Americano sofreu uma significativa rotação, no sentido dextral, durante o tempo decorrido entre o Cretáceo Superior e o Recente. É admissível supor que essa rotação tenha sido associada ao grande vulcanismo eocênico anteriormente referido.

A evidência gravimétrica foi delineada a partir do Mapa Bouguer da Bacia de Campos elaborado por Jahnert (1987). Nesse mapa, destaca-se uma faixa na direção SW-NE, com 80 a $150 \mathrm{~km}$ de espessura, representativa de anomalia gravimétrica positiva situada aproximadamente a $300 \mathrm{~km}$ da costa do Estado do Rio 


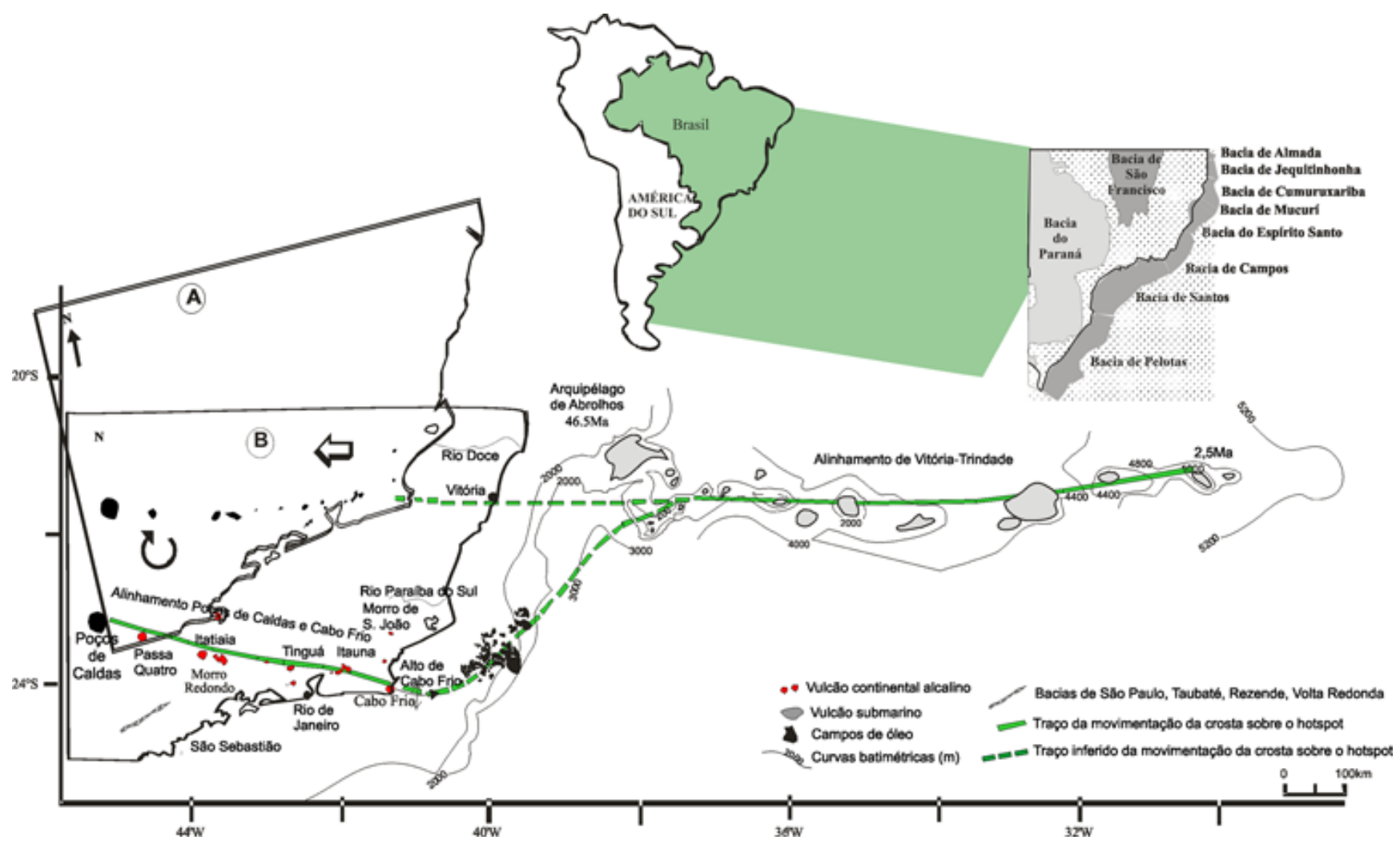

Figura 6 - O alinhamento de rochas alcalinas Poços de Caldas-Cabo Frio (Estado do Rio de Janeiro) e sua provável continuidade na Cadeia Vitória-Trindade (modificado de Thomaz-Filho \& Rodrigues 1999).

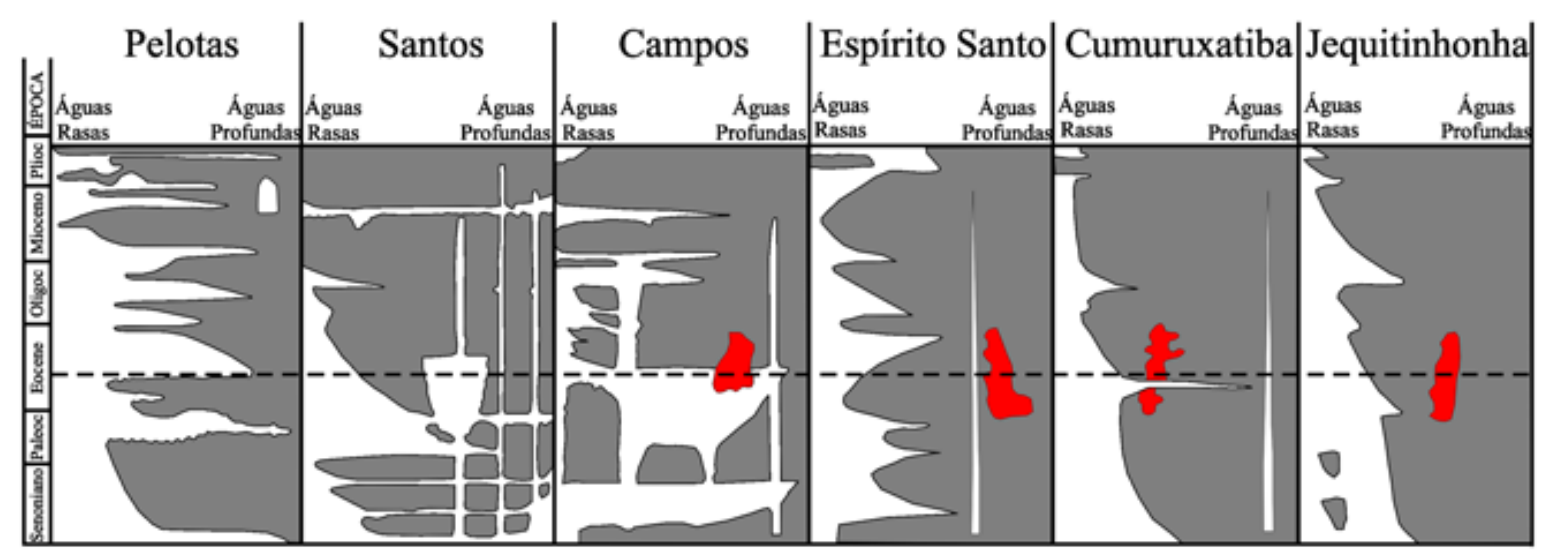

Rochas Vulcânicas

Rochas sedimentares

Figura 7 - Sedimentação de águas rasas e profundas nas bacias sedimentares marginais do leste e sudoeste do Brazil. As rochas vulcânicas das bacias de Campos, Espirito Santo, Cumuruxatiba e Jequitinhonha são de idade eocênica. As áreas claras na direção horizontal representam descontinuidades na sedimentação das bacias (Dias et al. 1994, Pereira \& Feijó 1994, Ragel et al. 1994, Santos et al. 1994, Vieira et al. 1994).

de Janeiro. O autor admitiu que essa faixa teria se destacado pela ocorrência de rochas ígneas de composição básica.

A evidência tectônica pode ser observada no mapa do Oceano Atlântico Sul e adjacências do continente Sul-Americano elaborado por Meisling et al. (2001), mostrando as anomalias gravimétricas obtidas a partir satélite (Sandwell \& Smith 1997) (Fig. 9). São 


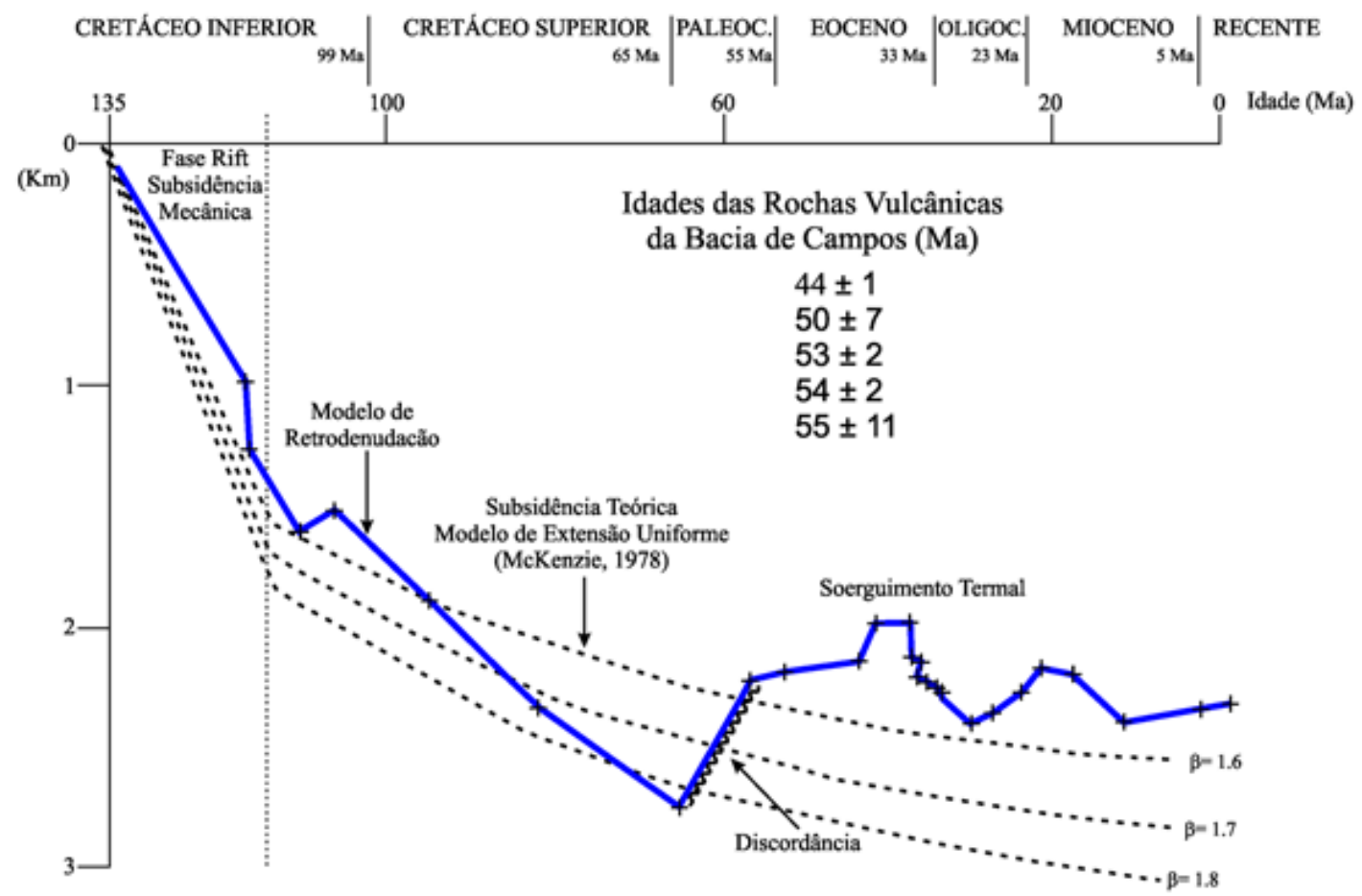

Figura 8 - Curva de subsidência tectônica (mecânica + termal) obtida por análise de retrodenudação (backstripping) de um poço da Bacia de Campos, comparada com as curvas de subsidência teóricas de McKenzie (1978). E notável o soerguimento termal (de aproximadamente $700 \mathrm{~m}$ ) no Paleoceno/ Eoceno, ou seja, coevo com o magmatismo na Bacia de Campos (modificado de Scarton 1993).

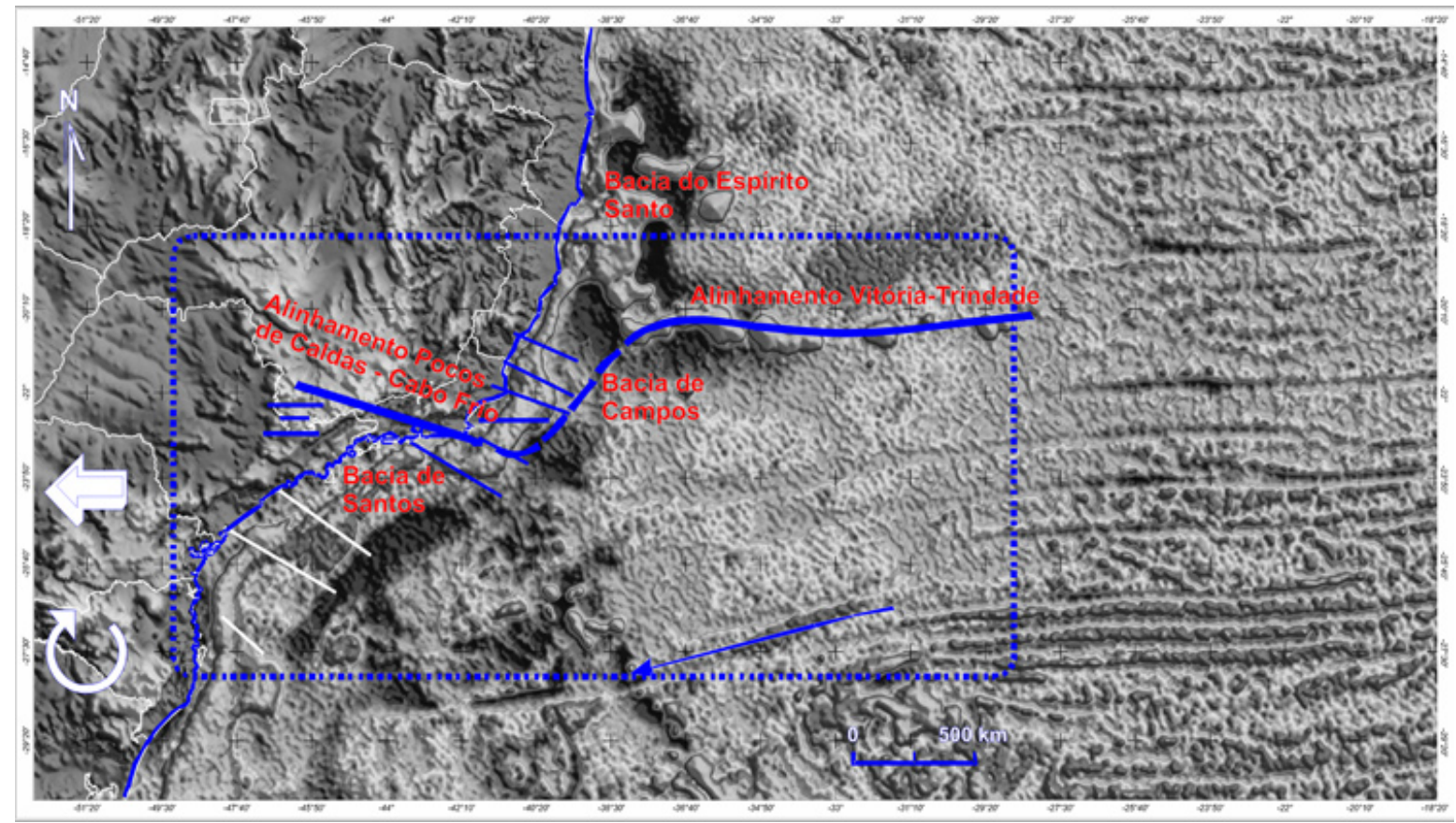

Figura 9 - Mapa do Oceano Atlântico Sul e continente Sul-Americano, mostrando anomalias magnéticas oceânicas obtidas a partir de altimetria por satélite (modificado de Sandwell \& Smith 1995). As falhas transformantes, nas partes mais próximas do continente Sul-Americano, mostram nitida inflexão para sudoeste. As falhas de transferência das baciasde Santos e Campos também são mostradas (modificado de Meisling et al. 2001). 
notáveis e proeminentes as inflexões para SW das falhas transformantes oceânicas, na medida em que se aproximam da margem continental sudeste brasileira. Por outro lado, as falhas de transferência das bacias de Santos e de Campos, das quais resultaram as falhas transformantes durante os estágios iniciais do rifteamento que separou a América do Sul da África, apresentam direção NW-SE, o que significa colocá-las em pronunciado ângulo com as falhas transformantes, $\mathrm{o}$ que poderia ser explicado pela rotação dextral do continente Sul-Americano.

CONSIDERAÇÕES FINAIS Quanto à exploração de petróleo nas bacias paleozóicas, abrem-se algumas possibilidades a partir do sistema petrolífero mostrado nas exsudações de óleo da região leste do Estado de São Paulo. Faz-se necessário o desenvolvimento de pesquisas geofísicas que se mostrem adequadas para identificar a distribuição dos corpos magmáticos, sob a forma de diques e soleiras, situados sob a Formação Serra Geral, no caso da Bacia do Paraná. Talvez, em condições de mais sucesso, devido à não ocorrência da espessa cobertura magmática da Bacia do Paraná, essas condições poderiam ser encontradas nas bacias paleozóicas do Solimões, Amazonas e Parnaíba.

Quanto ao magmatismo do Neocomiano nas bacias sedimentares marginais, é necessário desenvol- ver pesquisas sísmicas e, mesmo, realizar perfurações exploratórias, visando comprovar a ocorrência de sedimentos sotopostos aos basaltos hoje considerados como o embasamento econômico das bacias de Campos, Santos e Pelotas.

Quanto ao magmatismo do Cretáceo Superior, parece lógico admitir-se que eventos tectônicos dessa natureza devem produzir alterações significativas nas bacias marginais. São conhecidas as manifestações magmáticas de caráter intrusivo e extrusivo nessas bacias e são conhecidas, também, as discordâncias sedimentares que ocorrem nos intervalos estratigráficos do Cretáceo Superior. No entanto, permanecem ainda sob a necessidade de estudos mais aprofundados as alterações estruturais sofridas pelas bacias naquele tempo, assim como as suas conseqüências nos processos de geração, migração e acumulação de petróleo.

Quanto ao magmatismo do Eoceno, a coincidência entre o alinhamento dos campos de petróleo da Bacia de Campos (SW-NE), assim como a sua superposição sobre o aparente caminho do "hot spot", por sob a bacia, devido à rotação dextral do continente Sul-Americano, deve ser considerado em pelo menos dois importantes aspectos na evolução sedimentar da bacia: aquecimento necessário à geração de petróleo e os eventos estruturais e estratigráficos que tal associação teria provocado na bacia.

\section{Referências}

Almeida F.F.M. 1983. Relações Tectônicas das Rochas Alcalinas Mesozóicas da Região Meridional da Plataforma Sul_Americana. Rev. Bras. Geoc., 13(3):139-158.

Almeida F.F.M. 1986. Distribuição Regional e Relações Tectônicas do Magmatismo Pós-Paleozóico no Brasil. Rev. Bras. Geoc., 16(4):325-349.

Almeida F.F.M. 1991. O Alinhamento Magmático de Cabo Frio. In: SBG, Simp. Geol. Sudeste, 2, Rio de Janeiro, Atas, 2, p. 423-428.

Alves D.B. \& Rodrigues R. 1985. Influência das intrusões ígneas nos folhelhos devonianos da Bacia do Baixo Amazonas. Revista Brasileira de Geociências, 15(2):110115.

Araújo L.M., Trigüis J.A., Cerqueira J.R., Freitas L.C. da S. 2000. The Atypical Permian Petroleum System of the Paraná Basin, Brazil. In: Mello M.R. \& Katz B.J. (eds.) Petroleum Systems of South Atlantic Margins. AAPG Memoir, 73:377-402.

Araújo C.C. de, Yamamoto J.K., Rostirolla S.P., Madrucci V., Tankard A. 2005. Tar Sandstones in the Parana Basin of Brazil: Structural and Magmatic Controls of Hydrocarbon Charge. Marine and Petroleum Geology, 22:671685.

Araújo C.C. de, Yamamoto J.K., Rostirolla S.P. 2006. Arenitos Asfálticos na Bacia do Paraná: Estudo das Ocorrências no Alto Estrutural de Anhembi. Boletim de Geociências da Petrobras, 14(1):47-70.

Caputo M. \& Silva O.B. 1990. Sedimentação e Tectônica da Bacia do Solimões. In: Raja Gabaglia G.P. \& Milani E.J. (coords.) Origem e Evolução de Bacias Sedimentares. Petrobras, 415 p.

Conceição J.C.J., Zalán P.V., Dayan H. 1993. Deformações em Rochas Sedimentares Induzidas por Intrusões Magmáticas: Classificação e Mecanismos de Intrusão. Boletim de Geociências da Petrobras, Rio de Janeiro, 7(1/4):57-91d.

Cordani U.G. 1970. Idade do Vulcanismo no Oceano Atlântico Sul. Bol. IGA, 1:9-75

Cordani U.G. \& Blazecovic A., 1970. Idades Radiométricas das Rochas Vulcânicas dos Abrolhos. In: SBG, Congr. Bras.Geol. XXIV, Anais, p.265-270.

Cordani U.G. \& Teixeira W. 1979. Comentários Sobre as Determinações Geocronológicas Existentes para as Regiões das Folhas Rio de Janeiro, Vitória e Iguape, Carta Geológica do Brasil ao Milionésimo, Folhas Rio de Janeiro (SF.23), Vitória (SF.24) e Iguape (SG.23). MME, DNPM, Apêndice I, 175-207.

Dias J.L., Sad A.R.E., Fontana R.L., Feijó F.J. 1994. Bacia de Pelotas. Boletim de Geociências da Petrobras, 8(1):235245.

Ernesto M. 1996. Determinação da Curva de Deriva Polar Aparente para o Mesozóico da América do Sul. Tese de Livre Docência, IAG/USP, 56 p.

Ernesto M., Marques L.S., Piccirillo E.M., Molina E.C., Ussami N., Comin-Chiaramonti P., Bellieni G. 2002. Paraná Magmatic Province - Tristan da Cunha Plume System: Fixed versus Móbile Plume, Petrogenetic Considerations and Alternative Heat Sources. J. Volcanol. 
Geotherm. Res., 118:15-36.

Figueiredo M.M.A. \& Milani E.J. 2000. Petroleum Systems of South American Basins. In: Cordani U.G., Milani E.J., Thomaz-Filho A., Campos D.A. (eds.) Tectonic Evolution of South America, p. 689-718.

Fletcher C.J.N. \& Litherland M. 1981. The Geology and Tectonic Setting of the Velasco Alkaline Province, Eastern Bolívia. J. Geol. Soc. London, 138(5):541-548.

Fodor R.V.J., Mckee E.H., Asmus H.E. 1983. K-Ar ages and the opening of the South Atlantic Ocean: basaltic rock from the Brazilian Margin. Marine Geol., 54:M1-M8.

Herz N., 1977. Timing of Spreading in the South Atlantic: Information from Brazilian Alkalic Rocks. Geol. Soc. Am. Bull., 88:101-112.

Jahnert R.J. 1987. Gradiente Geotérmico da Bacia de Campos. Bol. Geoc. Petrobrás, 1(2):183-189.

Macedo J.M., Bacoccoli G., Gamboa L.A.P. 1991. O Tectonismo Meso-Cenozóico da Região Sudeste. In: SBG, Simp. Geol. Sudeste, 21, São Paulo, Boletim de Resumos, p.429-437.

McKenzie D.P. 1978. Some Remarks on the Development of Sedimentary Basins. Earth Planet. Sci. Lett., 40:25-32.

Meisling K.E., Cobbold P.R., Mount V.S. 2001. Segmentation of an Obliquely Rifted Margin, Campos and Santos Basins, Southeastern Brazil. Am. Assoc. Pet. Geol. Bull., 85(11):1903-1924.

Mizusaki A.M.P. \& Mohriak W.U. 1992. Sequências Vulcano-Sedimentares na Região da Plataforma Continental de Cabo Frio, RJ. In: SBG, Congr. Brasil. Geol., 37, São Paulo, Anais, 2:468-469.

Mizusaki A.M.P., Alves D.B., Conceição J.C.J. 1994. Eventos Magmáticos nas Bacias do Espírito Santo, Mucuri e Cumuruxatiba. In: SBG, Congr. Bras. Geol., 37, Camboriú (SC), Anais, p.566-568.

Mizusaki A.M.P., Thomaz-Filho A., Cesero P. de. 1998. Ages of the Magmatism and the Opening of the South Atlantic Ocean. Pesquisas, 25(2):47-57.

Mizusaki A.M.P., Thomaz-Filho A., Milani E.J., Césero P.de. 2002. Mesozoic and Cenozoic Igneous Activity and its Tectonic Control in Northeastern Brazil. Journal of South American Earth Sciences, 15:183-198.

Mohriak W.U., Barros A.Z., Fujita A.M. 1992. Magmatismo e Tectonismo Cenozóico na Região de Cabo Frio, RJ. In: SBG Congr. Bras. Geol. 36, Natal, Anais, 6:2873-2885.

Mohiak W.U. 2004. Recursos Energéticos Associados à Ativação Tectônica Mesozóica-Cenozóica da América do Sul. In: Mantesso-Neto V., Bartorelli A., Carneiro C.D.R., Brito-Neves B.B. (org.) Geologia do Continente Sul-Americano - Evolução da Obra de Fernando de Almeida, cap. XVIII, p. 293-318.

Pereira M.J. \& Feijó F.J. 1994. Bacia de Santos. Boletim de Geociências da Petrobras, 8(1):219-234.

Ragel H.D., Martins F.A.L., Esteves F.R., Feijó F.J. 1994. Bacia de Campos. Boletim de Geociências da Petrobras, 8(1):203-218.

Rodrigues R. 1995. A Geoquímica Orgânica na Bacia do Parnaíba. Tese de Doutorado, Universidade Federal do Rio Grande do Sul (UFRGS), Porto Alegre, RS, 225p.

Sadowski G.R. \& Dias Netto C. de M. 1981. O Lineamento
Tectônico de Cabo Frio. Rev. Bras. Geoc., 11(4):209212.

Sandwell D.T. \& Smith W.H.R. 1997. Marine Gravity Anomaly from Geosat and ERS-1 Satellite Altimetry. J. Geophys. Res., 102:10039-10050.

Santos C.F., Gontijo R.C., Araújo M.B., Feijó F.J. 1994. Bacias de Cumuruxatiba e Jequitinhonha. Boletim de Geociências da Petrobras, 8(1):185-190.

Scarton J.C. 1993. Análise Estratigráfica do Terciário Inferior da Bacia de Campos - Uma Visão Moderna (com ênfase na Região dos Campos Petrolíferos de Corvina e Malhado). Tese de Doutoramento, IG/UFRGS, 2vol., $403 \mathrm{p}$.

Siedner G. \& Mitchell J.G. 1976. Episodic Mesozoic Volcanism in Namibia and Brazil: K-Ar Isochron Study Bearing on the Opening of the South Atlantic. Earth Planetary Science Letters, 30:292-302.

Thomaz-Filho A. 1982. Ocorrência de Arenito Betuminoso em Anhembi (SP) - Cubagem e

Condicionamento Geológico. In: Congr.Bras.Geologia, 32, Salvador, Anais, 5:2344-2348.

Thomaz-Filho A. \& Rodrigues A.L. 1999. O Alinhamento de Rochas Alcalinas Poços de Caldas-Cabo Frio (RJ) e sua Continuidade na Cadeia Vitória-Trindade. Rev. Bras. Geoc., 29(2):189-194.

Thomaz-Filho A., Mizusaki A.M.P., Milani E.J., Cesero P. de. 2000. Rifting and Magmatism Associated with the South América and África Break Up. Revista Brasileira de Geociências, 30(1):017-019.

Thomaz-Filho A., Cesero P.de, MIzusaki A.M.P., Leão J.G. 2005. Hot spot Volcanic Tracks and their Implications for South American Plate Motion, Campos Basin (Rio de Janeiro State), Brazil. Journal of South American Earth Sciences, 18(3-4):383-389.

Thomaz-Filho A., Antonioli L., Camargo G.N. 2006. Evolução Tectono-Sedimentar das Bacias Marginais Brasileiras em seus Estágios de Rifte e de Mares Restrito, Nerítico, Batial e Abissal - Comparações com os Riftes do Leste Africano, Mar Vermelho e Golfo do Aden. In: Congresso Brasileiro de Geologia, 43, Aracajú, Anais, ST02:A0-382, p. 102.

Thomaz-Filho A., Mizusaki A.M.P., Antonioli L. 2008. Magmatism and Petroleum Exploration in the Brazilian Paleozoic Basins. Marine and Petroleum Geology, 25:143151.

Thompson R.N., Gibson S.A., Mitchell J.G., Dickin A.P., Leonardos O.H., Brod J.A., Greenwood J.C. 1998. Migrating Cretaceous-Eocene Magmatism in the Serra do Mar Alkaline Provinces, SE Brazil: Melts from the Deflected Trindade Mantle Plume? J. Petrol., 39(8):14931526.

Vieira R.A.B., Mendes M.P., Vieira P.E., Costa L.A.R., Tagliari C.V., Bacelar L.A.P., Fijó F.J. 1994. Bacia do espírito Santo e Mucuri. Boletim de Geociências da Petrobras, 8(1):191-202.

Manuscrito BR 24

Submetido em 20 de dezembro de 2007 Aceito em 19 de maio de 2008 